\title{
Metodologia de Desenvolvimento de Sistemas de uma Fábrica de Software Acadêmica: Estudo de Caso do Sistema para Controle de Jogos Olímpicos
}

\author{
Tharles de Sousa Andrade ${ }^{1}$, Renata Luiza da Costa ${ }^{2}$, Elymar Pereira Cabral ${ }^{3}$ \\ 1,2, 3 Departamento Acadêmico - Área de Informática - Instituto Federal de Educação, \\ Ciência e Tecnologia de Goiás (IFG) Av. Universitária s/n Vale das Goiabeiras - \\ 75.000-000 - Inhumas - GO - Brasil \\ tharles.andrade@academico.ifg.edu.br, renata.costa@ifg.edu.br, \\ professorelymar@gmail.com
}

\begin{abstract}
This paper presents a case study with the system development methodology MDS-FSW [BRITO, SILVA and CABRAL 2013], used by the Academic Software Factory of Goiás Federal Institute. Such methodology is used looking for the quality of the software development by students and teachers of the institution. Observations showed that its application triggered advantages in two aspects: In the quality of the academic software produced; In the learning of trainees students of the Factory.

Resumo. Este artigo apresenta um estudo de caso da metodologia de desenvolvimento de sistemas da Fábrica de Software do Instituto Federal de Goiás - Câmpus Inhumas, a MDS-FSW [BRITO, SILVA e CABRAL 2013]. Tal metodologia é utilizada visando à qualidade dos softwares desenvolvidos por alunos e professores da instituição. As observações mostraram que sua aplicação desencadeou vantagens na: qualidade dos softwares acadêmicos; aprendizagem dos alunos estagiários da Fábrica.
\end{abstract}

\section{Introdução}

O mercado de trabalho de Tecnologia da Informação (TI) torna-se cada dia mais exigente quanto à qualidade dos produtos e serviços prestados. Nesse sentido, a engenharia de software tem mostrado o quanto um software bem projetado e a metodologia de trabalho para sua concretização influenciam na qualidade final (Pressman e Maxim 2016).

Dalmon e Brandão (2013, p.114) afirmam que "aprimorar a etapa de desenvolvimento pode aumentar o impacto para o usuário final de projetos na área de Informática na Educação, influenciando os prazos de entregas, reduzindo os defeitos nos aplicativos e respondendo com maior agilidade na correção e adição de novas funcionalidades”. Atrelado a isso, destaca-se o próprio grau de uso do sistema que serve como parâmetro para saber sua qualidade em relação às funcionalidades esperadas.

Além disso, no contexto do aprimoramento e desenvolvimento profissional dos alunos e professores, Gomes Filho et al. (2015) desenvolveram um método baseado na simulação do ambiente do desenvolvimento de sistemas utilizando processos ágeis.

Diante das preocupações mencionadas a respeito da produção de softwares, Brito, Silva e Cabral (2013) desenvolveram a metodologia MDS-FSW visando atender as necessidades específicas de uma fábrica de software. Por essas razões, este texto 
VI Congresso Brasileiro de Informática na Educação (CBIE 2017)

Anais do XXVIII Simpósio Brasileiro de Informática na Educação (SBIE 2017)

apresenta uma aplicação da MDS-FSW para o desenvolvimento de um dos sistemas da Fábrica de Software do IFG - Câmpus Inhumas, o Sistema para Controle das Olimpíadas do Instituto Federal de Goiás.

\section{A metodologia de desenvolvimento de sistemas FSW}

A metodologia de desenvolvimento de sistemas FSW foca, principalmente, em padronizar os processos de desenvolvimento de software para garantia da qualidade de seus produtos. Ela é dividida em três processos: processo de iniciação, processo de execução e processo de entrega. Esses processos são demonstrados na Figura 1 abaixo.

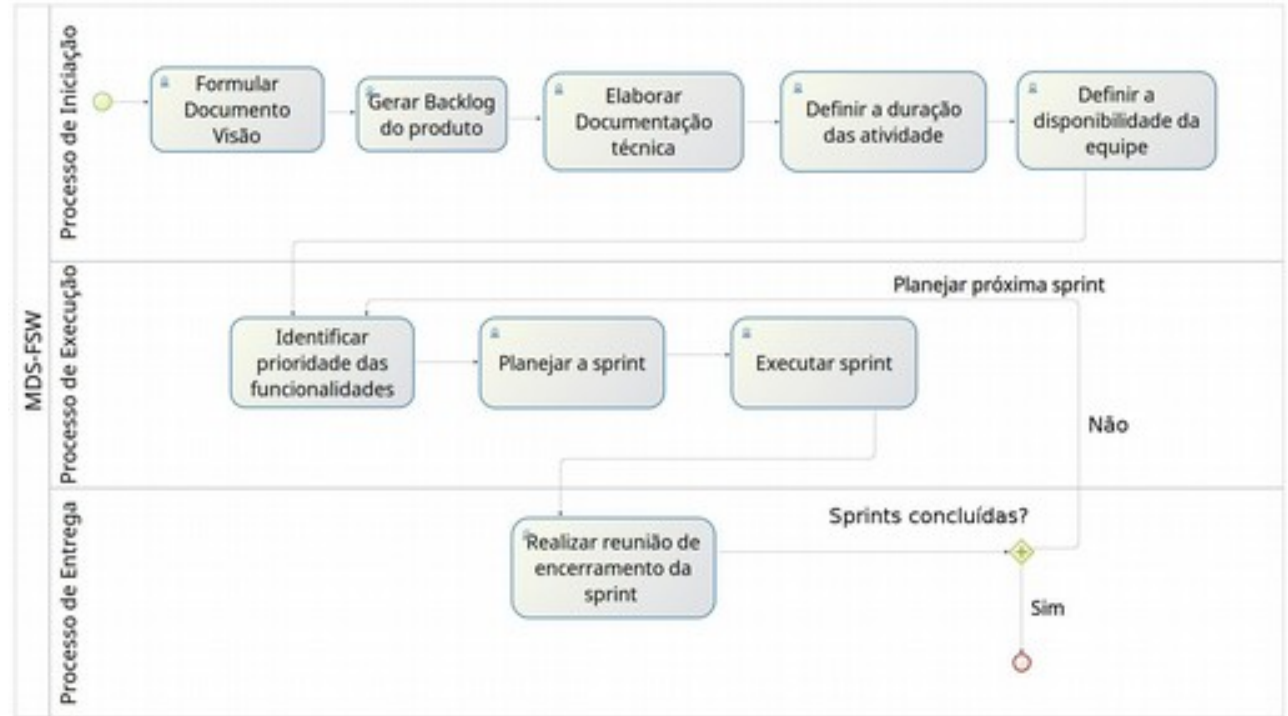

Figura 1. Processos da MDS-FSW. Fonte: Adaptado de Brito et al, 2013.

O processo de iniciação é a fase em que são definidos os requisitos do sistema levantados com o cliente. Nesse processo, são realizadas as atividades: elaboração do documento visão (texto com a visão geral do sistema); backlog do produto (desejos e necessidades do cliente); documentação técnica (diagrama/descrição dos casos de uso e Modelo Entidade-Relacionamento); definição da duração das atividades e disponibilidade da equipe de desenvolvimento [Brito, Silva e Cabral 2013].

A fase seguinte, etapa de execução, envolve a codificação das funcionalidades identificadas na fase anterior. Nela, são planejadas e executadas as sprints (ciclos de execuções e entregas de funcionalidades do produto). Também nessa etapa, são identificadas as prioridades das funcionalidades para a organização da sequência de execução das sprints [Brito, Silva e Cabral 2013].

Finalmente, tem-se a fase de entrega: é realizada a reunião de encerramento da sprint para validação da codificação e definições de melhorias a serem adotadas na próxima sprint. Quando finalizados os processos de execução e entrega das sprints, o cliente avalia as funcionalidades de acordo com a definição do backlog. Ele poderá aprová-las ou não. Caso sejam reprovadas, as sprints voltarão para o processo de execução para adequação às exigências do cliente. [Brito, Silva e Cabral 2013].

\section{Estudo de caso: a implementação do SCOL}

O SCOL, Sistema para Controle dos Jogos Olímpicos institucionais, foi modelado de acordo com as necessidades apresentadas pelos membros da comissão organizadora da 
Olimpíadas do Instituto Federal de Goiás (OLINFEG). Tal sistema visa automatizar os processos de organização e gerenciamento dos jogos da OLINFEG desde a inscrição das equipes até o encerramento dos jogos. Ele foi implementado utilizando a metodologia MDS-FSW e, por essa razão, foi selecionado para ser abordado no corrente texto.

Na primeira etapa, fase chamada iniciação, o SCOL teve sua concepção, análise e modelagem realizadas por estudantes de uma turma do curso de Técnico em Informática durante os anos 2013 e 2014, sob orientação de docentes das áreas de Projeto de Software e Banco de Dados.Na fase de execução, após a modelagem do sistema, a mesma turma definiu as prioridades das sprints (funcionalidades) a serem codificadas. Em seguida, concluíram parcialmente a implementação do SCOL sob orientação de docentes da área de Programação para Web.

$\mathrm{Na}$ etapa da entrega, os alunos apresentam o código-fonte da funcionalidade implementada na reunião de encerramento da sprint e o coordenador da Fábrica de Software faz avaliação e revisão do código. Todas essas ações foram cumpridas.

Esses processos atendem às recomendações de Pressman e Maxim (2016) sobre as atividades genéricas da metodologia (comunicação, planejamento, modelagem, construção e entrega) do processo de desenvolvimento de softwares.

Durante o desenvolvimento do SCOL, constatou-se a necessidade de algumas adaptações da metodologia proposta por Brito, Silva e Cabral (2013). Essas mudanças ocorreram nas etapas de execução e entrega removendo as reuniões diárias e a avaliação final do cliente de cada sprint (passou a ocorrer na entrega final). Tais alterações ocorreram devido à indisponibilidade de discentes e docentes envolvidos no projeto.

\section{Conclusão}

Foi observado que a metodologia MDS-FSW possibilita vivência integrada e prática das fases do processo de desenvolvimento de um sistema computacional. Além disso, vale destacar que o ambiente da fábrica de software proporcionou aos estudantes envolvidos experienciar algo muito próximo de um ambiente real de trabalho levantando discussões sobre a importância de habilidades interpessoais para o mercado profissional. No caso do SCOL, essas habilidades puderam ser desenvolvidas na fase de modelagem e implementação por meio da necessidade de comunicação, capacidade de escutar, negociação, trabalho em equipe, etc.

\section{Referências}

Brito, M. C. A.; Silva, F. P.; Cabral, E. P. (2013) "Elaboração de uma metodologia de desenvolvimento de software em uma instituição de ensino". Revista Brasileira de Informática na Educação (RBIE), v. 21, n. 02, p. 52.

Pressman, R. S. e Maxim, B., R. (2016) Engenharia de Software: uma abordagem profissional. 8 a ed. Porto Alegre: AMGH. 421 p.

Dalmon, D. L.; Brandão, L. de O. (2013) "Sobre o Desenvolvimento de Software Educacional: proposta de uma Linha de Produto de Software para Módulos de Aprendizagem Interativa”. RBIE, v. 21, n. 03.

Gomes Filho, et al. (2015) "Sabadágil: Métodos Ágeis de Desenvolvimento de Software aplicado ao Ensino”. RBIE, v. 23, n. 03. 